\title{
Why we Prototype! An International Comparison of the Linkage between Embedded Knowledge and Objective Learning
}

\author{
Anders Berglund ${ }^{\mathbf{1}}$ \& Larry Leifer ${ }^{2}$ \\ ${ }^{1}$ Integrated Product Development, School of Industrial Engineering and Management, KTH Royal Institute \\ of Technology, Stockholm, Sweden \\ ${ }^{2}$ Center for Design Research, Stanford University, Stanford, USA
}

Corresponding author:

Anders Berglund, School of Industrial Engineering and Management, KTH Royal Institute of Technology, Brinellvagen 85, 10044 Stockholm, Sweden,

Email: andersb5@kth.se, Phone: +46 (0) 87907808

\section{Abstract}

Prototypes are made, presented, and interpreted differently by people according to their understanding and frame of reference. Design educators have, in recent decades, come closer to one another in how they approach design creativity. Still, many distinct differences exist. One of the most striking has to do with the role of prototyping in developing ideas into concrete manifestations. Prototypes unlock cognitive association mechanisms related to visualisation, prior experience, and interpersonal communication in ways that favour iterative learning between peers in the product development community. When, where, and how to use prototyping strategies depends on context, and it demands a high level of situation awareness. The nature of this awareness is, in turn, dependent on cultural variables and curriculum development. Prototyping has been portrayed as an excellent activity to share inner thoughts, yet a deeper connection to its knowledge-building processes has been lacking in previous research. This paper builds on related literature in shaping a common understanding of how prototyping is perceived and applied in two different high-performance academic contexts (Stanford University, Stanford, USA, and the KTH Royal Institute of Technology, Stockholm, Sweden). Our exploration focuses on students' perceived learning experiences and on teachers' experiences within engineering design projects. Prototyping is an active enabler in both cases, establishing iterative loops of new knowledge through social interaction and team-based communication. The deeper level of cognitive attachments to prototyping provides an explicit link between embedded implicit knowledge and its consequences for objective learning.

Keywords: prototyping, engineering design, knowledge, learning

\section{Introduction}

This paper provides perspectives and ideas on how to use and integrate prototyping in engineering education. From a designer's point of view, a lot has emerged since 
Vygotsky (1962) studied the behaviour as an intellectual process. The way individual knowledge is shared and actively constructed in social learning environments has evoked a design perspective that concern ubiquitous social design activity (Brereton et al. 1996). From such a perspective, implicit and explicit interactions relate to different types of behavioural, i.e. proactive or reactive, design-based processes that allow for generalizability of methods (Ju \& Leifer 2008). With a scarce amount of research contrasting the implicit nature and intellectual knowledge boundaries of prototyping, together with its pragmatic use in engineering design projects, this research set out to strengthen such a link.

Individual learning is, from this viewpoint, rooted in interactions, and it is discoveryoriented by nature. Criticisms and shortcomings of this fundamentally constructivist view have been brought forward (Phillips 1995, Liu \& Matthews 2005). Still, engineering education highlights its essentiality in concern for student learning and interactions between engineers. Together, engineers are responsible for designing and explicitly converging their inner thoughts into creative realisations and innovations (Sternberg \& Lubart 1999, Dym et al. 2005). Creativity in the context of engineering design is linked to problem solving and other cognitive activities. Understanding the nature of a problem put design-oriented practices in a cyclic use of divergent and convergent pattern of reasoning (Dym et al. 2005). Engineering design produces an array of feasible alternatives, any one of which has the potential to be the final product. Engineering creativity, then, requires a special set of skills in order to: 1) decide on what to prototype, 2) chose the most appropriate prototype media, and 3) place the prototype in the most advantageous framework for its audience and creators. Cognitive attachments or aspects thereof give prototypes a common language that can be shared universally. The rationales of design are communicated through prototypes, stimulating reflections, that are used to frame, refine, and discover possibilities (Lim et al. 2008). Research from the science of learning shows that prior knowledge plays a critical role in how students progress through a problem, what they learn, and what they produce (NRC 2003, Adams et al. 2010). For engineers, idea generation and prototyping can be merged through hands-on activity. In parallel with other methods for generating ideas, prototyping defines lateral thinking in which divergence and systematic thinking are unified (von Hippel 1988). Although prototyping is undoubtedly an important factor for engineers and engineering designers in particular, earlier work expresses a lack of awareness of the benefits to early-phase innovation (Carleton \& Cockayne 2009).

Prototypes are categorised differently among scholars, using either three dimensions: physical-tangible, analytic-virtual, and experiential-behavioral (Edelman 2011); or a two dimensional perspective: physical and analytical (Ulrich \& Eppinger 2007). The exception in the experiential-behavioural prototypes, express representations of behaviours that could break traditional and established patterns of behaviour. This exploration of new behaviours is captured as "relieving individuals of the responsibility to consciously change what they do" (Coughlan et al. 2007, p6). Physical prototypes are tangible approximations of the intended product, whereas analytic or 'virtual' (Liou 2008) versions are more commonly used to create a detailed and mathematically correct model of a specific product component. High-resolution virtual prototypes are seen as flexible and easily modified, a factor which facilitates accuracy when adjustments are made to vital data needed for predictions. Early stages of a virtual prototype could be in the character of a conceptual model that aims to validate user requirements and should be initiated early in the development process. Despite the user-oriented nature of many analytic models, requirement errors are difficult to detect as the size and complexity of the prototype increases. In contrast, physical prototypes still play an important role in illustrating and communicating functionality. Conceptual variations provide a suitable medium for an early representation of functional requirements also in physical form. The simplicity and usability of physical prototyping accounts for its strength in helping teams to make the intangible 
(i.e. ideas) tangible. In a way that might seem counterintuitive, low-resolution prototypes foster divergent thinking about the nature of the problem and the solution (Edelman 2011). This form of communication is particularly relevant during periods of rapid change in the evolution of products and services. This is almost always a requirement in early development stages and can still play a critical role in advanced stages where circumstances and demands change.

Prototypes serve several purposes: they function as guiding milestones, they show tangible progression or demonstrate specific features, and they enable systems integration, ensuring components and subsystems work together as planned (Chua et al. 2003). To assure confidence in the prototyping process, the predictive power is vital to bring earlier versions forward. Prototypes externalise thoughts and make people talk, but the dialogue between people and prototypes is more important than creating a dialogue among people alone (Cross et al. 1994). Depending on the type of design, prototyping can take on different forms while still denoting similarities in the final manufactured form. Prototypes allow ideas to emerge from tacit formats. Learning is influenced through integrative skills and problemsolving modes (Pisano 1996). As a consequence, the activity of building prototypes and communicating through prototypes has a central role in all phases of product development (e.g. feasibility testing, subsystem functionality, proof of concept, and market testing).

Prototyping supports idea generation, conceptualisation, design exploration, evaluation, communication, and construction. Because it can be an overwhelming undertaking to create a single prototype that strives to achieve all of these goals, it is important to be focused on objectives. From an educational viewpoint, achieving learning objectives overshadows the importance of technical performance, even though they tend to go hand in hand. Prior studies argue greater attention should be paid to the functionality and role of prototyping in engineering education (Cross et al. 1994, Chua et al. 2003). Correspondingly, this paper seeks to further delineate the ways in which prototyping drives contextdependent learning in engineering education. A contemplative comparison between two geographically distant and culturally distinct learning environments is investigated in search of premises on how the power of prototyping activities in engineering education can be cultivated.

\section{Research setting and method}

This paper uses existing views and beliefs relating to learning, knowledge, and prototyping to build a phenomenological intercept. The array of perspectives that characterise the ambiguity toward prototyping is outlined to provide a deeper understanding of why prototyping is approached and used differently in engineering education. In an international comparison, the study looks at two masters-level engineering design project courses: Project-Based Engineering Design, Innovation, and Development (ME310) at Stanford University, USA and the Integrated Product Development (IPD, MF2036) at KTH, Sweden. The authors have decades of combined experience in prototyping activities as part of the courses, and this experience has served as a backbone for their research and reflections. The comparison was initiated through site visits, during which various prototyping activities were either taking place as part of assignments ('missions' in new product development) or set gate deliveries. In cases where the visiting researcher conducted interviews and observed the activities undertaken by students, this type of cross-checking comparison looked at various documented evidence (e.g. mock-ups, various 2D and 3D sketches, quickand-dirty CAD samples) produced during the different stages of the student work process. Researchers also reviewed student project reports to triangulate amongst assessment measures. These observations were scattered across the start-to-finish project timeline. 
They occurred daily during periods of intense prototyping activity. The combined role of monitoring and facilitating students did not require any activities specifically designed for this research. Rather, the activity that was subject to interpretation was based on the decisions and actions made by the students themselves.

In-depth interviews were made with a dozen project members at each location. Brief quotes from these interviews are used to strengthen and provide objectivity to the experiential views expressed. In each interview, probing techniques were used to obtain a qualitative understanding of the influence, character, problems and benefits of prototyping. Interviews focused on the different types of prototyping made, time spent on them, and physical resources used. Interviewees were selected based on their active engagement in prototyping activities (a potential research bias). Open-ended interviews occurred at random times; during the act of prototyping, and in follow-up stages. The intent was to map the impact of actions taken to specific prototyping events and artefacts in a manner that would strengthen or alter subsequent interpretations.

\section{Prototyping from a holistic perspective}

The unique strength of the prototyping model lies in how it facilitates communication between people across disciplines and roles. Conceptual prototyping (to distinguish it from physical prototyping) leads to shared experiences and tangible collaboration with others. It also builds understanding through experimentation and demonstrates a range of feasible manifestations. Prototypes function as carriers of both static and dynamic knowledge. Efficient and timely knowledge transfer always facilitates the new product development process. Recognising that prototyping is a meta-cognitive activity that externalises knowledge, the authors find that it fits well with Nonaka's (1994) argument: “While tacit knowledge held by individuals may lie at the heart of the knowledge creating process, realising the practical benefits of that knowledge centres on its externalisation".

The kinds of knowledge that are generated through this iterative work process have been addressed through reference to a variety of different taxonomic types (Nonaka \& Takeuchi 1995, Nonaka et al. 2000). The key to the taxonomic approach to knowledge sharing is to identify specific conditions that facilitate exchange (Nonaka et al. 2000). Iterative prototyping promotes a wide range of knowledge and experience exchanges that are context dependent and framed by explicit learning requirements. In conveying knowledge, it is helpful to understand the duality of knowledge: namely, that it can be simultaneously objective and subjective (Brown \& Duguid 1991). Furthermore, the consensus/dissensus dimension orients participants toward different aspects of scientific discourse: e.g., normative, interpretive, critical, and dialogic (Alavi \& Leidner 2001). Prototypes are from a schematic viewpoint representations (virtual, physical or experiential) that shift in character in a way similar to how knowledge representations are perceived to exist, explicit or factual knowledge, and tacit knowledge or 'know how' (Schultze \& Leidner 2002). The fluidity of knowledge brings distinctive perspectives into dialogue through the construction and visualisation of boundary objects (Carlile 2002) and through prototype cascades (Edelman 2011).

The dynamics of knowledge creation and the need for a platform of understanding argue for a knowledge perspective to be in place for successful knowledge transfers (Nonaka \& Takeuchi 1995, Nonaka et al. 2000). The interrelation of individual and collective knowledge is conceived to be a generative protocol for accumulating successes through stories and externalised means (e.g. prototypes) that carry meaning to a specific group of people (Brown \& Duguid 1991). 
In this process, interfunctional communication and coordination depend heavily upon the effectiveness of unarticulated translation and integrative procedures. Similar to the anecdote of the knowledge iceberg (Polanyi 1958, Stenmark 2001), where communicated and shared knowledge merely accounts for the visible surface representation, prototyping shares this dualistic imperative. Collaborative and individual manifestations are handled through either virtual or physical shapes. Knowledge dealt with in one mode might be difficult to transfer to the next. However, iterations can perform this function. This involves a combination of both explicit collaborative learning and/or tacit affordances that allow for intangible propositions to be processed, understood, and manifested.

Knowledge is socially sourced and constructed through social processes that include: access to guidance, observation, interaction with peers, and the sharing of workplace artefacts (Valsiner and Van der Veer 2000). Given the social roots of human knowledge, interaction between peers is crucial to the creation and reshaping that is manifest in boundary objects that allow for perspective taking and overall knowledge transparency (Boland \& Tenkasi 1995). Based on double-loop learning (Argyris 1982), the challenge and redesign of existing knowledge requires cognitive reframing. Prototyping allows embedded knowledge to take part in the reappropriation of, and integration of, 'sticky information' (von Hippel 1994). In relation to stated arguments, prototyping meets the requirements of lateral thinking and creative explorative communication.

\section{Prototyping manifests experiential learning}

Experiential learning deals with knowledge duality conflict as complex mental processes are perceived and translated into categories through active experimentation and reflective observation (Kolb 1984). Summarising Kolb's ideas, active learners test their beliefs through external activities and then use reflection to examine and manipulate gathered information introspectively. Notably, experiential learning explicitly juxtaposes the fundamental difference between learning in action versus learning through abstraction.

Active learners are experimentalists and benefit from working in collaboration with others, whereas reflective learners are theoreticians and tend to work by themselves or in 'micro' groups of just one other individual (Felder 1988). Engineering education research has found that engineers are likely to be categorised as active learners rather than reflective learners. This matches well with their role in engineering teams (Felder 1988, Crawley et al. 2007).

Reassuringly, a proper understanding of how to use and apply prototypes can target individuals' ability to learn. As is shown in past research (Argyris 1982), individuals may have learned but the organisation may not have. Through prototyping, intangibles are decoded and understood by individuals working together. Unfortunately, these knowledge constructs face limitations on transfer within groups that can block collaborative consensus. Prototyping as a mean to produce an action-based knowledge state, or a status of 'knowing in action' (Cook \& Brown 1999) leads to different ways of assessing the role of what is known in an organisation's ability to learn, to maintain quality, to develop competencies, and ultimately to innovate.

In the everyday workplace, prototyping is an activity that can override dysfunctional communication structures and align knowledge representations in a collective representation. Engineers need early, up-front practice in the methods and techniques that will aid them in their daily work if these are to have any considerable impact on their work processes and target audiences. Prototyping, in particular, carries perhaps a greater value as a knowledge repository than work practices are sometimes able to reveal. Without 'good enough' exploration of the design space in search of suitable alternatives, subsequent design stages (analysis, testing, decision making) have no significant impact. 
One key to bringing about a reflective perspective and deepening the learning process for the individual would be to rethink and reframe ongoing negotiation during design processes. Understanding the learning process and how it works from a practical viewpoint may substantially increase the chances of developing and applying these abilities later in life (Felder 1988, Cross et al. 1994, Eris \& Leifer 2003).

\section{Prototyping in engineering design education}

Academia recognises an increasing trend in which student participation in the learning process is developed through teaching and learning strategies that foster distinctive skills rooted in academic achievements (Humphreys et al. 2001, Crawley et al. 2007). The range of personal transferable skills that students need to be able to display include communication and presentation skills, problem-solving and organisational skills, teamwork skills, and leadership skills (Sheppard et al. 2004). In such settings, engineering design students are incorporated in industry-sponsored projects to determine project requirements, benchmark alternatives, conceive solutions, and develop a series of increasingly sophisticated prototypes, followed by analysis and user testing.

The literature on engineering education has been heavily influenced by the didactical imperatives involved in functional knowledge and the essence of attaining pragmatic skills (Crawley et al. 2007). Acquiring in-depth engineering skills corresponds well with what is claimed as 'procedural knowledge' (Billett 1996), where knowing how provides a basis for cognitive development.

The design phase is associated with iterative loops that confront existing, prefabricated expressions of knowledge. To achieve optimised learning iterations, each loop should open up new opportunities in which surprising elements can appear. To optimise knowledge transitions between the learner and the facilitator is to embrace a repertoire of learners' actions: reframing, listening, reflecting, engaging in dialogue, and trying again (Schön 1983).

The integration effort of students working together is a visible struggle to grasp each other's thinking and prototype outputs. Conversely, students appreciate feedback (input) regarding their own thinking and prototyping. As a consequence, prototyping provides a tangible expansion of the shared understanding and experience base for peers. The learning progression in this structured but unpredictable process underpins an engineer's pragmatic skills (Crawley et al. 2007) and functional knowledge (Baillie \& Moore 2004) through adaptive and renegotiable conditions.

\section{Prototyping experiences in different educational settings}

A comparison between American and Swedish prototyping experiences (Stanford University and $\mathrm{KTH}$, Royal Institute of Technology) outlines a striking fundamental difference: prototyping is used differently as a learning tool depending on culture, approach to the phenomena, and overall attention from faculty to establishing innovative design. The Stanford University's ME310 corresponds to a need-driven engineering education, where pragmatic skills are required to be closely aligned with teamwork and project problemsolving approaches (Sheppard \& Leifer 1997). ME310 prototyping involves 'iterations', all intended to accelerate learning and cycle through the Kolb learning modes repeatedly, at varying levels of abstraction, with the explicit intention to deliver break-through innovation. At KTH the course builds on a generic product development process consisting of six phases (Ulrich \& Eppinger 2007): planning, concept development, system-level design, detail design, testing and refinement, and production ramp-up (final prototype). These phases are checked through a stage-gate procedure, which has been proven beneficial for 
quality assurance, coordination of project activities, planning and allocation of time, improvement identification, and overall support (Cooper 1990). The systematic use of formal deliveries is set to break up the innovation process into a predetermined set of stages, each consisting of prescribed, multifunctional and parallel activities. The main features of each course characteristics are outlined in Table 1.

Both courses are described as focused on providing students with the opportunity to define and build a complex product component or system from concept to functional prototype (Leifer 1997, Norell 1998, Berglund 2008, Berglund 2012). ME310 is today designed to be entirely global, each co-located Stanford team has a partner team at a university typically 6000 to 9000 miles away, and three to ten hours of time zone difference. The prerecognition of either partner university or their students is something that contrasts the learning challenge for the ME310 students in their collaborative interactive efforts. At KTH students may know each other a bit more as they have taken several courses together prior to MF2036, except for the international master-level students who have shared just a few compulsory courses together. Stanford masters degree students come from all over the world and there are very few instances of anyone knowing anyone else on day one of the project. This distinction separates the two contexts and outlines a line of differences, e.g., why we prototype differently.

Rather than challenging students with isolated mock-up scenarios, students are set out to define their own problem framing, including project requirements and build solutions for real companies. Prototyping is used as a continuous learning tool involving iterative feedback-loops with peers. This process allows critical questioning and a community of inquiry that slows down the progression somewhat, but simultaneously adds more depth to each step taken. The way in which updates, verifications, and overall progression are taken is paraphrased by a ME310 student as follows: "We test a lot of different things; this makes us really understand different ways of approaching our solution space".

Kolb uses a categorisation in which experiential learning goes through a four-mode process: diverging, assimilating, converging, and accommodating. These transformative modes have been vital for analysing and tracking project progress in Stanford's ME310. Where weak patterns of presence in the different modes has resulted in a project's with 'thank you' results when compared projects that iterated consistently and repeatedly through all modes tend to receive 'wow' recognition. Juxtaposing the duality of learning styles; a diverging style is good for idea-generating activities, whereas a converging style prefers technical tasks over tasks dealing with social or interpersonal issues. The assimilating style is found in individuals who are 'information brokers'; good at taking in a lot of information and ordering it logically. Hands-on experience and action-oriented learning best matches the accommodating learning style. A majority of the students interviewed related to how the different design missions made them: "keep an open approach", "not decide too early", "stretch and test ideas that would not have been considered" and "spend time on alternatives".

On a practical level, both courses function as a suitable and low-stakes training ground, where students pick up new experiences by doing and redoing. Collaboration as part of their interaction with other engineers places the complete design-related experience in a pragmatic simulation of how to conduct product development work as an engineering designer in real life. The biggest concern is with regards to the distributed sharing that takes place as part of the course setting. Students' comments included: "difficult to apply and use all perspectives involved" and "it is easier to discuss with on-site colleagues rather than having language and space to deal with". Students and faculty share the ambition to bring novelty, blending different techniques with one another to reinforce individual skills as well as collaborative efforts. In consideration for 'prototyping influence' students expressed: "massive", "could not believe we were capable of such creativity", "without a 
Table 1 Prototyping phases: cross-comparison of cases

Stanford ME310
Mission
Breakthrough
innovation on an
industry-sponsored
engineering design
challenge.

Business model
You are a start-up
consulting team and
the sponsor is your
first client.
Region
Silicon Valley, California,
USA, plus a partner
team in Europe or
Latin America.
Product
Design Development
Mission Element.
Critical function/
experience prototype

Dark Horse prototype

Funky

Function prototype.

\section{Process \\ Activity Description according to phase.}

\section{Critical function and/or} experience prototypes

Three-dimensional physical objects or enactments that are built to experiment with the most important product or service feature in the overall system solution space.

Dark horse prototypes

Three-dimensional physical prototypes that are built to test a previously rejected idea. The name comes from horse racing. The dark horse is unlikely to win, but has a higher payoff for betters, a breakthough.

\footnotetext{
System prototype

Made quickly and from the cheapest possible materials to gain an early awareness of the system integration challenges ahead, and to gain early user experience data.
}

\section{KTH MF2036}

Mission

Incremental-to-

radical innovation

patents are frequently

applied (industrial

partner presents a

problem area - a case

of concern).

\section{Business model}

You interact with medium to large enterprises, recently also small, researchbased start-ups.

\section{Region}

Sweden, with a predominance of the Stockholm region.

\section{Product}

Design Development. Proof of Concept.

\section{Planning}

Product specifications, project description, goals, deliminations, requirements, time plan, risk analysis, organisation, budget routines, stakeholder analysis, list of activities.

\section{Concept development Descriptions, evaluations, recommendations, project reorganisation, planning.}

\section{System level design}

Development of CAD drawings, initiation of FEM analysis possible first prototypes, proof of concept thinking.

\section{Team set-up}

Each project in MF2036

engages one team of approximately 15 individuals at KTH.

\section{Process}

Activity description according to phase.

\section{Project formation}

Setting working guidelines and internal 'rules of the game' perception of problem at hand.

Testing the boundaries Using different idea generation sessions, involving sketching, quick and dirty CAD, mock-ups.*

\section{Combining features} Ideas, establishing concepts where both design and function is screened to evaluate and preselect concepts. 
Table 1 (Continued)

\begin{tabular}{|c|c|c|c|}
\hline $\begin{array}{l}\text { Functional System } \\
\text { Integration } \\
\text { prototype using } \\
\text { engineering } \\
\text { materials, circuits, } \\
\text { and software }\end{array}$ & $\begin{array}{l}\text { Proof } \\
\text { that you can build the } \\
\text { solution, focus on } \\
\text { the functionality and } \\
\text { testing rather than fit } \\
\text { and finish }\end{array}$ & $\begin{array}{l}\text { Detail design } \\
\text { solution proposition } \\
\text { towards final } \\
\text { prototype, tests, } \\
\text { functionality } \\
\text { prototype. }\end{array}$ & $\begin{array}{l}\text { Proof } \\
\text { Overall fit, modularity } \\
\text { additional testing, } \\
\text { functionality are tuned } \\
\text { and altered. }\end{array}$ \\
\hline $\begin{array}{l}\text { Penultimate prototype } \\
\text { A forced closure } \\
\text { exercise all about } \\
\text { getting real. }\end{array}$ & $\begin{array}{l}\text { Final System } \\
\text { Integration, only fit and } \\
\text { finish left before the } \\
\text { public exhibition. }\end{array}$ & $\begin{array}{l}\text { Refinements } \\
\text { Iterative testing. }\end{array}$ & $\begin{array}{l}\text { Final System Validation } \\
\text { of final fitting, } \\
\text { refinements is } \\
\text { concentrated upon } \\
\text { aesthetic features, } \\
\text { pre-production } \\
\text { considerations. }\end{array}$ \\
\hline $\begin{array}{l}\text { Final prototype } \\
\text { delivered and } \\
\text { functional. }\end{array}$ & $\begin{array}{l}\text { Public Display } \\
50 \% \text { of the final grade } \\
\text { is for the engineered } \\
\text { system, } 50 \% \text { of } \\
\text { the final grade is } \\
\text { for thorough } \\
\text { documentation of the } \\
\text { entire missioning. }\end{array}$ & $\begin{array}{l}\text { Final prototype } \\
\text { delivered and } \\
\text { functional. }\end{array}$ & $\begin{array}{l}\text { Public display } \\
\text { Dual purpose, with } \\
\text { separate presentations } \\
\text { made: (a) industry- } \\
\text { focus on the final } \\
\text { prototype and (b) } \\
\text { academic/learning } \\
\text { objectives - focus } \\
\text { on prototype in } \\
\text { combination with } \\
\text { process and learnings. }\end{array}$ \\
\hline Final documentation & $\begin{array}{l}200-300 \text { Page } \\
\text { print and electronic } \\
\text { documentation that } \\
\text { counts for } 50 \% \text { of the } \\
\text { course grade and is } \\
\text { shared with the } \\
\text { industry project } \\
\text { sponsor. }\end{array}$ & Final documentation & $\begin{array}{l}\text { 100-200 Page } \\
\text { report besides individual } \\
\text { documentation and } \\
\text { grade based on: } \\
\text { Portfolio Lessons } \\
\text { learned Literature } \\
\text { seminar. Active } \\
\text { participation. }\end{array}$ \\
\hline
\end{tabular}

*Concept Development phase is also used for early prototype presentations, but not as a principal requirement.

doubt crucial if we were to bring it to an end", and "sometimes alternatives were forced forward, and not that easy to come up with".

At the KTH Royal Institute of Technology, the IPD master's level project course embraces pragmatic approach similar to that of ME310, but with two distinct differences: 1) Rather than a distributed team set-up, the class uses a large team of approximately 15 students who are highly dedicated to the process-oriented nature of prototyping refinements and 2) Prototyping is used less as a means to communicate early, up-front ideas, and more as an extension of first-round data analysis and information gathering.

As the KTH students come to their 'concept development' gate delivery, the 2D sketches are turned into both computer-aided design captures and numerous 3D mock-ups. One student explained: "We catch up with new ideas and angles to things we did not think of earlier when we get to materialise our thoughts". In terms of differences in learning styles, a diverging style that allows time on-task and for students to break apart and reorganise and reutilise existing beliefs is more tangible in the early phases at Stanford through the existence of prototyping deliverables, compared to KTH. Yet, this has moved towards earlier implementation and use throughout the last years. Specifically noted by students were: "we did numerous drawing idea generating activities where we collectively then used the ideas to sketch further more developed ideas" and "all kinds of ideas got documented, reviewed and decided upon". 
In contrast, students from more recent years have applied playful approaches where rough mock-ups and early CAD has been used to provide a deeper thought process concerning specific functions and design. Students explained: "We have really focused on distinct aspects each time we do these creative sessions", "you really become engaged and everyone contributes" and "if we had difficulties understanding a specific detail, the mock-ups made us be on the same wavelength". The systematic approach that scholars seek (e.g. Dym et al. 2005, Crawley et al. 2007) runs like a machine by the fifth year, where KTH students in particular have developed a self-regulated artistry that encompasses all four learning styles (Kolb 1984). The most apparent difference lies in the pre-course set-up, i.e. how much creative freedom and predefined workspace is provided upfront. The fixed set of deliverable gates was noted by one student as: "the gates force us to deliver, depending on expectancies (note: from the industrial partner), presentations are made to bring out our views... that hopefully they like".

\section{Discussion}

Rather than stepping around in safe territories, prototyping allows for uncertain balancing acts to take form, linking individual knowledge with externalised objectivity useful for learning and development. Prototyping involves the coordination of different knowledge types and levels (e.g. formal/informal, local/global, tacit/codified, personal/social, and software-embedded/people-embodied). Productivity requires functional integration of formal knowledge and pragmatic skills. In this process, every new object contains new knowledge and a new way for each individual to act upon it. This is the core of individual knowing (Brown \& Duguid 1991). By enabling an earlier set of productive inquiries, mock-ups provide items to be detected and critically screened at an early stage. This puts new ways in perspective, allowing a fruitful conversation with specialists and the industrial partner and lending greater support for functional knowledge and individual knowing to expand early in each project phase. Whereas ME310 bundles its development work within highly articulated prototyping missions, the IPD students at KTH follow a stepwise procedure to match and excel the expectations of the industrial partner. Placing intensified efforts on facilitating early-phase prototyping could open up perspectives beyond those existing in the project group internally. Two important factors have been set in place at KTH that trigger the maturity level of prototyping knowledge being iterated:

1. A mandatory prototyping course (six ECTS) for all enrolled masters-level students.

2. Coaches' increased awareness and efforts made to facilitate early up-front prototyping.

Prototyping must be assessed and understood in order to reveal how it is perceived and learned. The way in which students manifest creative experiences is perhaps best portrayed through the iterative process that students undertake as they play with prototypes in sophisticated manners. This process should be sought out, as it stands a chance to awaken the unexpected instead of confirming the findings of what is previously known. Prototyping allows illustrative examples to take form, where the intangible is put in a context that can be interpreted by multiple individuals and creates a vast perspective as part of a common language. There are different ways of dealing with prototyping in design learning situations, although they all seek to create knowledge about how to implement and apply suitable methods and tools. According to both cases prototyping is described as a mean to provide a common understanding, a common point of reference. By identifying potential problems or opportunities early up-front, either done through formalised activities or gate deliveries, prototyping is an efficient means of outlining and clarifying perspectives. 
The two courses are not overlapping in content, course design, or context, yet both are wholly dedicated to promoting design efforts that could be made useful in every aspect where prototyping is a feasible option. The design features of the two courses differ greatly:

- Stanford has, until recently, used a fixed assignment template that put students before a great variety of challenges while still carrying out a project together with an industrial sponsor (stakeholder). The assignments have been reformulated as mission statements that intend to open up the approach towards definition and scope. The mission emphasis is intended to take out fixation and linearity of thought patterns, provoking the unexpected not thought of.

- KTH uses stage-gate meetings that centralise process aspects, supporting methods, communication, and the fact that students take on real-life/industry work habits as a way to switch up the prototypes and other deliverables made. The final prototype is central, yet the nature of organising intra-group activities that supports prototyping activities concerns an overarching learning objective that surpasses any outcome derived attention. Over time, process concerns allow for efficiency to the advocated periods of building, testing, and refining.

Problem solving and creativity may well be captured in prototyping attempts, but design impressions alone are insufficient unless supported through a holistic framework.

Adams et al. (2010) have investigated how such courses influenced by problem-based learning deal with effective problem solving. Adding effectiveness is perhaps beyond the core of prototyping. However, this is not necessarily the case if you look at the implications it is set out to convey. In such a scenario, prototyping is immensely more complex than an activity that strives to solve routine or familiar problems. The realistic character that forms the foundation of both courses enables a way to recognise strategy and process.

\section{Conclusions}

Prototyping shares a universal tendency of merging individual beliefs and inner thoughts with expressed feelings and artefacts. Vygotsky (1962) uses the social interaction where 'language' acts as a mediator to accelerate individual understanding and consciousness. This paper asserts that prototyping plays the role of a boundary object, an 'expander' and a 'converger' of thought that fluidly enables a dialogue of construction and visualisation. Prototyping is based on social interaction and is especially suited to confronting complex problems. By using prototyping as a core activity in the courses, communication between project members, potential users and industrial partners becomes relatively easy, less abstract and creates fewer unnecessary misunderstandings. In combining and teasing out different aspects of knowledge, this paper offers a multifaceted perspective to the presentation, comparison, and analysis of prototyping. The comparison between the two unique contexts provides designer-based perspectives on educational practices. Design through prototyping carries several similarities across different contexts. Based on the reflections and interpretations made, engineering education should benefit from adopting more structured approaches to hybrids or 'copies' of the two courses. Such courses definitely already exist in many universities, yet the complexity and prototyping activities may certainly shift and open up doubts and weaknesses that need to be addressed. We have yet to see whether the use of a stage-gate approach and process-oriented focus, or more playful approaches and dedicated missions, is a step forward. There are different approaches in how to learn the tangible aspects of design creativity, and a number of versatile approaches can bridge individual creative dispositions.

We hope future research will further investigate the flourishing individual settings that can offer an extension to different curricula and best practices. Such attempts would explore 
different types of learning activities and distinct learning objectives across different working contexts. By adding to the prototyping palette, actionable attempts by educators can make improvements in how the phenomena is best utilised.

\section{References}

Adams, J., Kaczmarczyk, S., Picton, P. and Demian, P. (2010) Problem solving and creativity in engineering: conclusions of a three-year project involving reusable learning objects and robots. Engineering Education 5 (2), 4-17.

Adler, P. (1990) Shared learning. Management Science 36, 938-957.

Alavi, M. and Leidner, D.E. (2001) Review: knowledge management and knowledge management systems: conceptual foundations and research issues. MIS Quarterly 25 (1), 107-136.

Argyris, C. (1982) The executive mind and double-loop learning. Organizational Dynamics $11(2), 5-22$.

Baillie, C. and Moore, I. (2004) Effective learning and teaching in engineering. New York: Routledge Falmer.

Berglund, A. (2008) The experiences of an engineering design education project - the case of prototyping the next generation dishwasher door. In Proceeding of the International Conference on Intellectual Capital and Knowledge Management (ICICKM) 08'. New York.

Berglund, A. (2012) Do we facilitate an innovative learning environment? Student efficacy in two engineering design projects. Global Journal of Engineering Education 14 (1), 27-33.

Billett, S.R. (1996) Situated learning: bridging sociocultural and cognitive theorising. Learning and Instruction 6 (3), 263-280.

Boland, R.J. and Tenkasi, R.V. (1995) Perspective making and perspective taking in communities of knowing. Organization Science 6 (4), 350-72.

Brown, J.S. and Duguid, P. (1991) Organizational learning and communities of practice: toward a unified view of working, learning and innovation. Organization Science 2, 40-57.

Brereton, M.F., Cannon, D.M., Mabogunje, A. and Leifer, L.J. (1996) Collaboration in design teams: how social interaction shapes the product. In Analysing design activity (eds. Cross, N., Christiaans, H. and Dorst, K.), pp319-341. Chichester: John Wiley \& Sons, Ltd.

Carleton, T. and Cockayne, W. (2009) The power of prototypes in foresight engineering. In Proceedings from the $17^{\text {th }}$ International Conference of Engineering Design (ICED). Stanford, CA.

Carlile, P.R. (2002) A pragmatic view of knowledge and boundaries: boundary objects in new product development. Organization Science 13 (4), 442-455.

Chua, C.K., Leong, K.F. and Lim, C.S. (2003) Rapid prototyping principles and applications. Singapore: World Scientific Publishing Co.

Cook, S.D.N. and Brown, J.S. (1999) Bridging epistemologies: the generative dance between organizational knowledge and organizational knowing. Organization Science 10 (4), 381-400.

Cooper, R.G. (1990) Stage-gate systems: a new tool for managing new products. Business Horizons May-June, 44-54. 
Coughlan, P., Fulton Suri, J. and Canales, K. (2007) Prototypes as (design) tools for behavioral and organizational change - a design-based approach to help organizations change work behaviors. Journal of Applied Behavioral Science 43 (1), 1-13.

Crawley, E.F., Malmqvist, J., Östlund, S. and Brodeur, D.R. (2007) Rethinking engineering education: the CDIO approach. New York: Springer.

Cross, N., Christiaans, H., and Dorst, K. (1994) Design expertise amongst student designers. Journal of Art and Design Education 13 (1), 39-56.

Dym, C.L., Agogino, A.M., Eris, O., Frey, D.D. and Leifer, L.J. (2005) Engineering design thinking, teaching and learning. Journal of Engineering Education 94 (1), 103-120.

Edelman, J. (2011) Understanding radical breaks: media and behavior in small teams engaged in redesign scenarios. Dissertation at Stanford University, Dept. of Mechanical Engineering, Center for Design Research.

Eris, O. and Leifer, L.J. (2003) Facilitating product development knowledge acquisition: interaction between the expert and the team. International Journal of Engineering Education 19 (1), 142-152.

Felder, R.M. (1988) Learning and teaching styles in engineering education. Journal of Engineering Education 78 (7), 674-681.

von Hippel, E. (1988) The sources of innovation. New York, NY: Oxford University Press.

von Hippel, E. (1994) 'Sticky information' and the locus of problem-solving. Management Science 40 (4), 429-439.

Humphreys, P., Lo, V., Chan, F. and Duggan, G. (2001) Developing transferable group work skills for engineering students. International Journal of Engineering Education 17, 59-66.

Ju, W. and Leifer, L. (2008) The design of implicit interactions: making interactive systems less obnoxious. Design Issues 24 (3), 72-84.

Kolb, D.A. (1984) Experiential learning: experience as the source of learning and development. Englewood Cliffs, N.J: Prentice-Hall.

Leifer, L. (1997) Suite-210: A Model for Global Product-Based Learning With Corporate Partners, ASME Curriculum Innovation Award.

Lim, Y.-K., Stolterman, E. and Tenenberg, J. (2008) The anatomy of prototypes: prototypes as filters, prototypes as manifestations of design ideas. ACM Transactions on Computer-Human Interaction 15 (2), article 7.

Liou, F.W. (2008) Rapid prototyping and engineering applications - a toolbox for prototype development. Boca Raton, FL: CRC Press, Taylor \& Francis Group.

Liu, C.H. and Matthews, R. (2005) Vygotsky philosophy: constructivism and its criticisms examined. International Education Journal 6 (3), 386-399.

Nonaka, I. (1994) A dynamic theory of organizational knowledge creation. Organization Science 5 (1), 14-37.

Nonaka, I. and Takeuchi, H. (1995) The knowledge creating company: how Japanese companies create the dynamics of innovation. New York, NY: Oxford University Press.

Nonaka, I., Toyama, R. and Konno, N. (2000) SECl, Ba and leadership: a unified model of dynamic knowledge creation. Long Range Planning 33, 5-34.

Norell, M. (1998) Competitive industrial product development needs multi-disciplinary knowledge acquisition. In The Design Productivity Debate (ed. A.H.B.Duffy), pp100-109. London: Springer-Verlag. 
NRC (2003) How People Learn: Brain, Mind, Experience, and School. National Academies Press.

Phillips, D.C. (1995) The good, the bad, and the ugly: the many faces of constructivism. Educational Researcher 24 (7), 5-12.

Pisano, G. (1996) The development factory: unlocking the potential of process innovation. Cambridge, MA: Harvard Business School Press.

Polanyi, M. (1958) Personal knowledge: toward a post-critical philosophy. Chicago, IL: University of Chicago Press.

Schultze, U. and Leidner, D.E. (2002) Studying knowledge management in information systems research: discourses and theoretical assumptions. MIS Quarterly 26 (3), 213-242.

Schön, D. (1983) The reflective practitioner. How professionals think in action. London: Temple Smith.

Sheppard, S. and Leifer, L. (1997) Reality brings excitement to engineering design education. In Proceedings of the Workshop on Computing Futures for Engineering Design. Pasadena, CA: Harvey Mudd College.

Sheppard, S., Chen, H.L., Schaeffer, E., Steinbeck, R., Neumann, H. and Ko, P.-J. (2004) Evaluating student achievement in collaborative groups in undergraduate engineering through peer assessment models. A National Science Foundation report.

Sternberg, R.J. and Lubart, T.I. (1999) The concept of creativity: prospects and paradigms. In Handbook of creativity (ed. R.J. Sternberg), pp3-5. New York, NY: Cambridge University Press.

Stenmark, D. (2001) Leverage tacit organizational knowledge. Journal of Management Information Systems 5 (3), 9-24.

Ulrich, K.T. and Eppinger, S.D. (2007) Product design and development, 4th edn. Singapore: McGraw Hill.

Valsiner, J. and Van der Veer, R. (2000) The social mind: construction of the idea. Cambridge University Press.

Vygotsky, L.S. (1962) Thought and language. Cambridge, MA: MIT Press. 